2014-4

\title{
Real-Time Control of Shunt Active Power Filter under Distorted Grid Voltage and Unbalanced Load Condition Using Self Tuning Filter
}

\author{
Samet Biricik \\ Technological University Dublin \\ Soydan Redif \\ University of Lefke \\ Ozgur Ozerdem \\ Near East University - Cyprus
}

See next page for additional authors

Follow this and additional works at: https://arrow.tudublin.ie/engscheleart2

Part of the Electrical and Electronics Commons

\section{Recommended Citation}

Biricik, S., Redif, S., Ozerdem, C., Khadem, S.K., and M. Basu. Real-Time Control of Shunt Active Power Filter under Distorted Grid Voltage and Unbalanced Load Condition Using Self Tuning Filter. IET Power Electronics. Available online April, 2014. DOI:10.1049/iet-pel.2013.0924

This Article is brought to you for free and open access by the School of Electrical and Electronic Engineering at ARROW@TU Dublin. It has been accepted for inclusion in Articles by an authorized administrator of ARROW@TU

Dublin. For more information, please contact

arrow.admin@tudublin.ie, aisling.coyne@tudublin.ie, gerard.connolly@tudublin.ie.

Funder: European Commission

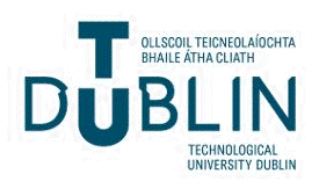




\section{Authors}

Samet Biricik, Soydan Redif, Ozgur Ozerdem, Shafiuzzaman K. Khadem, and Malabika Basu 


\title{
Real-Time Control of Shunt Active Power Filter under Distorted Grid Voltage and Unbalanced Load Condition using Self Tuning Filter
}

\author{
Samet Biricik $^{\text {ab }}$, Soydan Redif ${ }^{\mathrm{b}}$, Özgür C. Özerdem ${ }^{\mathrm{c}}$, Shafiuzzaman K. Khadem ${ }^{\mathrm{d}}$, Malabika Basu ${ }^{\text {* }}$ \\ *Corresponding author \\ ${ }^{\text {a }}$ School of Electrical \& Electronic Engineering, Dublin Institute of Technology, Dublin, Ireland \\ ${ }^{\mathrm{b}}$ Department of Electrical \& Electronic Engineering, European University of Lefke, North Cyprus \\ 'Department of Electrical \& Electronic Engineering, Near East University, North Cyprus \\ ${ }^{\mathrm{d}}$ School of Engineering, Trinity College Dublin, Dublin, Ireland
}

\begin{abstract}
In this study, an alternative control method is proposed to improve the harmonic suppression efficiency of the active power filter in a distorted and unbalanced power system to compensate the perturbations caused by unbalanced non-linear loads. The proposed method uses a selftuning filter (STF) to process the grid voltage in order to provide a uniform reference voltage to obtain the correct angular position of the phase locked loop. Moreover, the required compensation currents are obtained by implementing another STF to the transformed set of currents in order to separate the fundamental and harmonic currents. This allows the calculation of precise reference current for unbalanced, non-linear and variable load conditions. The proposed control method gives an adequate compensating current reference even for non ideal voltage and unbalanced current conditions. The realtime control of the filter under the distorted and unbalanced power system is developed in RT-LAB realtime platform. Results obtained in the SIL (software-in-the-loop) configuration are presented to verify the effectiveness of the proposed control technique.
\end{abstract}

Index Terms- Active power filter, Park transformation, Clark transformation, self tuning filter, unbalanced load currents and voltages.

\section{Introduction}

Awareness of the quality and reliability/security of the power supply has increased in recent years due to a number of reasons. The main reason is technological advancement in conventional and non-conventional power generation, exploitation of renewable energy sources and their integration into supply networks and finally utilization of highly sophisticated devices in the end users equipment, all of which required to be ensured with desired power quality [1]. Suppression of harmonic currents, generated due to harmonic voltages in the supply side and the non-linear loads, is one of the most 
important and dominating components for power quality improvement. The shunt active power filter (APF) has been shown to alleviate these problems, drawing much attention since its introduction in 1976 by Gyugyi and Strycula [2]. The shunt APF has excellent compensation characteristics and is able to simultaneously suppress harmonic currents and compensate for reactive power. To achieve this, the power converter of an APF is controlled to generate a compensation current that is equal to the harmonic and reactive currents.

The rapid progress in the development of modern power electronic devices and DSP technology has led to a greater concentration on the improvement of APFs. In order to determine the harmonic and reactive components of the load current, several techniques are introduced in the literature [3]. These strategies play a very important role in the improvement of steady state and dynamic performances and the stability of the filter. The common point of the control techniques is the requirement of a grid voltage measurement [4]. The unbalanced voltages usually occur because of variations in the load characteristics over time and/or the unbalanced nature of the load, which could arise, for example, from different phases of the load current due to variations of impedances. Therefore, the dynamic characteristics of the harmonic detection methods would likely be adversely affected without proper consideration of the condition of grid voltages and currents. Some methods are proposed to increase the harmonic suppression efficiency of APF controlled by $p-q$ theory in [34,5-10], $p-q-r$ theory in [11]. All these algorithms require some kind of low-pass or high-pass filters to extract the fundamental or harmonic components. In $[12,13]$, a neural network based solution is proposed for the control of shunt APFs operating under distorted voltage conditions.

Self-tuning filter (STF) was initially developed to estimate the phase angle of pulse width modulation (PWM) converter outputs [14]. It was then applied to solve the control problem of shunt APF in distorted voltage condition [15]. The STF algorithm was shown to possess important advantages over other methods in the case of unbalanced and distorted source voltages; however, specifics on the control system were not divulged in those papers. Since then much attention has been devoted to the application of the STF to the control of APFs [16-31]. To date, the STF algorithm has only been adapted to $p-q$ theory and the $d q$ method, referred to here as STF-based $p q$ 
theory (STF- pq) [18-24, 31] and STF-based $d q$ method (STF-dq) [15,24,25], respectively. Abdusalam et al. (2007) [16] proposed the integration of STF algorithm with $d-q$ theory for the control of hybrid APFs (HAPFs), where a shunt APF was connected in series with a shunt passive filter. Karimi et al. (2008) [17] also showed how the STF can be used to control a shunt APF by integrating it with $p q$ theory, and referred to the resultant system as selective bandpass filtering. Abdusalam et al. (2008 \& 2009) applied STF-based control with $p$-q theory for voltage signals in [18] and current signals in [19], without the use of low-pass or high-pass filters.

The STF was also used for both voltage and current signals in [19, 20]. Gupta et al. (2010) used the STF- pq under name of harmonic tuned filter in [21]. Samadaei et al. (2011) also used STF- $p q$ to control shunt APF connected in series with the shunt passive filter in [24]. In [27], the STF- pq theory is first used in the control of multilevel shunt APF by Benaissa et al, (2012). By this method the number of filters is reduced in the control system. However, the effectiveness of the control algorithm is only tested under balanced currents with ideal grid voltage conditions. Ghadbane et al. (2012) used the STF- pq theory, where the STF is applied to the load current only [28]. Ghamri et al. (2012) proposed an STF- pq based method, where the STF was first used to extract the harmonic currents from load currents with subsequent application of $p q$ theory [29]. Biricik et al. (2011) in [25] showed that the harmonic suppression performance of both the $p q$ and $d q$ control methods deteriorates in the case of distorted source voltages. The authors propose applying an STF- pq based control strategy to improve the harmonic suppression efficiency of a HAPF and solve the problems caused by unbalanced and distorted source voltages in [30].

In this paper, an alternative control method is proposed to increase the harmonic suppression efficiency of three phase, three wire APF in the case of unbalanced and distorted grid voltage conditions by processing the load currents through the STF only. This eliminates the requirement of any high-pass or low-pass filtering as otherwise required by $d q, p q, p q r$ theories etc. The algorithm can be successfully applied under variable and unbalanced load conditions. The main contributions of this paper are the following: 
- The algorithm does not necessitate pre-processing, such as high-pass and lowpass filtering, in order to separate the fundamental and harmonic components;

- Performance of the system is evaluated with distorted and unbalanced grid voltages and with unbalanced, non-linear, variable load groups;

- The detailed model and the algorithm has been implemented in RT-LAB realtime simulator platform, developed by OPAL-RT, to evaluate the real time performance of the proposed control method of the Shunt APF in a 3-phase 3wire system.

\section{Review of APF Control Methods}

This section briefly reviews three techniques for the estimation of the reference compensation current of the APF. A description of the well-known (conventional) $p-q$ and $d-q$ methods is presented, which is followed by a description of the STF-based $p-q$ theory method in [19]. The reader is referred to [19, 34] for a more detailed treatment of the methods.

\subsection{Instantaneous Active Power Theory ( $p$-q Theory)}

The instantaneous and reactive power method, proposed by Akagi [34], remains one of the most popular APF control schemes. It first transfers the voltages and currents from the three-phase $a-b-c$ phase coordinates to a two-phase coordinate system $\alpha-\beta-0$, via Clarke transformation. Then the active and reactive instantaneous powers are calculated. Generally, each of the active and reactive powers is composed of continuous and alternating terms. The continuous term corresponds to the fundamentals of current and voltage. The alternating part represents power related to the sum of the harmonic components of current and voltage. A low-pass filter or high-pass filter is required to separate continuous and alternating terms of active and reactive instantaneous powers. The three phase reference current of the APF is obtained by applying the inverse Clarke transform to the stationary reference currents.

\subsection{Stationary Reference Frame Method ( $d-q$ Method)}

The $d-q$ method is the second most studied control method in the literature. This method is based on the Park transformation. First, the load currents are transformed into the component in the $d-q$ coordinate system in order to separate the fundamental and harmonics components of instantaneous currents $\left(i_{d}, i_{q}\right)$. One of the main differences of 
this method from p-q theory is that the $\mathrm{d}-\mathrm{q}$ method requires the determination of the angular position of the synchronous reference of the source voltages; for this a PLL algorithm is used. After the transformation of load currents into the synchronous reference, a low-pass or high-pass filter is using to separate the fundamental and harmonic components. Finally, the reference currents are transformed to the three phase reference using the inverse synchronous transform.

\subsection{Self-Tuning Filter-Based Instantaneous Active and Reactive Theory}

As mentioned earlier, the STF algorithm was first used to estimate the phase angle of the PWM converter outputs in [14]. As mentioned in Section 1, this algorithm is mostly used with the $p q$ theory to solve the problems caused by unbalanced and distorted grid voltages. In [19], the STF is applied to filter out the voltage harmonics from the grid voltages, which are then used in the $p q$ theory. Here, the STF also acts to balance the voltages. Moreover, a second STF is applied to the load currents, $i_{\alpha}$ and $i_{\beta}$, to obtain the harmonic currents, $i_{\alpha}$ and $i_{\beta}$, which are then used in the $p q$ theory.

\section{Proposed Control Method}

The purpose of the APF is to dynamically compensate the reactive and harmonic current. Current drawn by the three-phase load with a non-unity power factor harmonics is given by:

$$
i_{L}(t)=i_{1}(t)+i_{h}(t)+i_{q}(t)
$$

where $i_{L}(t)$ is the load current, $i_{1}(t)$ is the fundamental current, $i_{h}(t)$ is the harmonic currents and $i_{q}(t)$ is the reactive current. Conventionally, shunt APF is operated as a current source in parallel with the load. The power converter of an APF is controlled to generate a compensation current, $i_{c}(t)$, which is equal in magnitude to the reactive and harmonic current of the load and opposite in phase, i.e.,

$$
i_{c}(t)=-\left[i_{h}(t)+i_{q}(t)\right]
$$

This yields a sinusoidal source current given by 


$$
i_{S}=i_{1} \sin (\omega t) .
$$

In the proposed control method, the load currents $\left(i_{L a}, i_{L b}, i_{L c}\right)$ are transformed first into the components of the synchronous reference frame coordinate system by using the Park transformation:

$$
\left[\begin{array}{l}
i_{d} \\
i_{q}
\end{array}\right]=\sqrt{\frac{2}{3}}\left[\begin{array}{ccc}
\cos \theta & \cos \left(\theta-\frac{2 \pi}{3}\right) & \cos \left(\theta+\frac{2 \pi}{3}\right) \\
-\sin \theta & -\sin \left(\theta-\frac{2 \pi}{3}\right) & -\sin \left(\theta+\frac{2 \pi}{3}\right)
\end{array}\right],
$$

where, the angle $\theta$ is the angular position of the synchronous reference. It is a linear function of the angular position of the grid voltages. This angular position can be determined by the aid of a phase-locked-loop (PLL). Therefore, the performance of the control method is dependent on the type of PLL algorithm used. In order to improve the efficiency of the PLL, the three-phase supply voltages $\left(u_{a}, u_{b}, u_{c}\right)$ are transformed using the Clarke (or $\alpha-\beta$ ) transformation into a different coordinate system by using:

$$
\left[\begin{array}{l}
u_{\alpha} \\
u_{\beta}
\end{array}\right]=\sqrt{\frac{2}{3}}\left[\begin{array}{ccc}
1 & -\frac{1}{2} & -\frac{1}{2} \\
0 & \frac{\sqrt{3}}{2} & -\frac{\sqrt{3}}{2}
\end{array}\right]\left[\begin{array}{l}
u_{a} \\
u_{b} \\
u_{c}
\end{array}\right] .
$$

In order to obtain undistorted and balanced waveform for the control circuit, the $\alpha-\beta$ of the distorted grid voltage is processed through the STF. In [19], the transfer function of the STF is obtained by integration of the synchronous reference frame and it is defined as:

$$
H(s)=\frac{V_{x y}(s)}{U_{x y}(s)}=K_{x} \frac{s+j \omega}{s^{2}+\omega^{2}},
$$

where

$$
V_{x y}(t)=e^{j \omega t} \int e^{-j \omega t} U_{x y}(t) d t
$$

The STF has a magnitude and phase response that is similar to those of a general band-pass filter. Apart from the integral effect on the input magnitude, the STF does not alter the phase of the input, i.e. the input $\mathrm{U}_{\mathrm{xy}}(\mathrm{s})$ and output $\mathrm{V}_{\mathrm{xy}}(\mathrm{s})$ have the same phase. 
Note that in order to have unit magnitude, i.e. $|\mathrm{H}(\mathrm{s})|=0 \mathrm{~dB}$, a constant $K_{X}$ is incorporated in to (6) [19], that is,

$$
H(s)=\frac{V_{x y}(s)}{U_{x y}(s)}=K_{X} \frac{\left(s+K_{X}\right)+j \omega}{\left(s+K_{X}\right)^{2}+\omega^{2}} .
$$

In the stationary reference, the fundamental components $\left(\bar{u}_{\alpha}, \bar{u}_{\beta}\right)$ are given by:

$$
\begin{aligned}
& \bar{u}_{\alpha}(s)=\frac{K_{1}}{s}\left[u_{a}(s)-\bar{u}_{\alpha}(s)\right]-\frac{\omega}{s} \bar{u}_{\beta}(s), \\
& \bar{u}_{\beta}(s)=\frac{K_{1}}{s}\left[u_{\beta}(s)-\bar{u}_{\beta}(s)\right]+\frac{\omega}{s} \bar{u}_{\alpha}(s) .
\end{aligned}
$$

The obtained un-distorted and balanced two phase voltages can be converted to the three phase system by using inverse Clark transformation as given by,

$$
\left[\begin{array}{l}
\bar{u}_{a} \\
\bar{u}_{b} \\
\bar{u}_{c}
\end{array}\right]=\sqrt{\frac{2}{3}}\left[\begin{array}{cc}
0 & 1 \\
\frac{\sqrt{3}}{2} & -\frac{1}{2} \\
-\frac{\sqrt{3}}{2} & -\frac{1}{2}
\end{array}\right]\left[\begin{array}{l}
\bar{u}_{\alpha} \\
\bar{u}_{\beta}
\end{array}\right]
$$

In this method the angular position $(\theta)$ of the source voltages is determined correctly by the PLL. The un-balanced nature of load currents is also an important power quality issue that may reduce the performance of the APF. For this reason, the obtained $i_{d}$ and $i_{q}$ components by (4) are also processed in the proposed control method in order to calculate balanced current components.

$$
\begin{aligned}
& \bar{i}_{d}(s)=\frac{K_{2}}{s}\left[i_{d}(s)-\bar{i}_{d}(s)\right]-\frac{\omega}{s} \bar{i}_{q}(s), \\
& \bar{i}_{q}(s)=\frac{K_{2}}{s}\left[i_{q}(s)-\bar{i}_{q}(s)\right]+\frac{\omega}{s} \bar{i}_{d}(s) .
\end{aligned}
$$

After obtaining the balanced and undistorted current components, the harmonic components of instantaneous currents $\left(\tilde{i}_{d}, \tilde{i}_{q}\right)$ are obtained by 


$$
\tilde{i}_{d}=i_{d}-\bar{i}_{d},
$$

and

$$
\tilde{i}_{q}=i_{q}-\bar{i}_{q} \text { respectively. }
$$

In most of the control methods, a low-pass or high-pass filter is used to separate the fundamental and harmonic currents. However, there is no need for an additional filter in the proposed control method. Finally, the obtained current harmonic components, from (14) and (15), are then transformed to the three phase converter reference currents using the inverse synchronous transform given by,

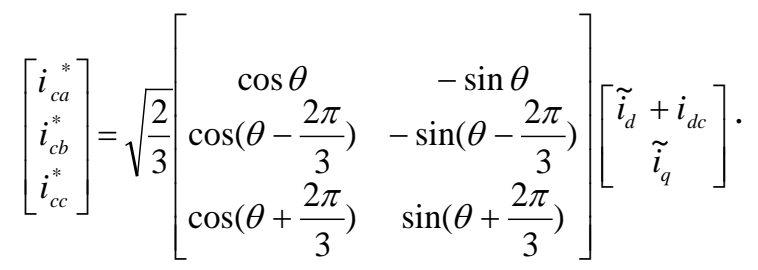

In order to compensate for the converter active losses, the DC-link capacitor voltage is processed by a conventional proportional-integral (PI) regulator, which gives a measure of the active power losses in the converter. To generate accurate converter reference currents an additional fundamental component $\left(i_{d c}\right)$ has been added, which is derived from the PI of the dc regulator. The reference converter currents are compared with the actual converter currents and the error is processed through a PI and passed through a hysteresis comparator to derive the final switching signals for the converters.

\section{Power Circuit and Measurement Description}

To test the proposed algorithm a (3Ø, 3-wire) Voltage Source Inverter is connected in parallel with the load, as shown in Fig. 1 . The grid voltages $\left(u_{a}, u_{b}, u_{c}\right)$ and the load currents $\left(\mathrm{i}_{\mathrm{La}}, \mathrm{i}_{\mathrm{Lb}}, \mathrm{i}_{\mathrm{Lc}}\right.$ ) are the sensing requirements. Single-phase Resistor Capacitor type rectifier supplied non-linear loads $\left(\operatorname{Load}_{1}, \operatorname{Load}_{2} \& \operatorname{Load}_{3}\right)$ and a threephase RL type rectifier supplied non-linear load $\left(\operatorname{Load}_{4}\right)$ are used to evaluate the dynamic performances of the system. The resistances of the RC loads are not equal with the others. Consequently, the three-phase load currents are not balanced. Additionally, a linear RL type load ( $\operatorname{Load}_{5}$ ), which is connected between phase-a and phase-b, is used to create additional unbalance current condition in the studied system. Analysis shows 
that the fundamental active power $(\mathrm{P})$ is $29.4 \mathrm{~kW}$; the fundamental reactive power $(\mathrm{Q})$ is $7.4 \mathrm{kVAr}$ when all the loads are connected. The details of the system parameters can be found in Table I.

TABLE I: PARAMETERS OF THE ANALYSED SySTEM

\begin{tabular}{|c|c|c|}
\hline Symbol & Quantity & Value \\
\hline $\mathrm{v}_{\mathrm{s}, f}$ & Line to Neutral Volt. \& Freq. & $240 \mathrm{~V}, 50 \mathrm{~Hz}$ \\
\hline $\mathrm{Z}_{\mathrm{s}}$ & Grid Line Impedances & $3 \mathrm{~m} \Omega, 2.6 \mu \mathrm{H}$ \\
\hline $\mathrm{Z}_{\mathrm{c}}$ & Converter Coupling Impedances & $20 \mathrm{~m} \Omega, 2 \mathrm{mH}$ \\
\hline $\mathrm{Z}_{\mathrm{L}}$ & Load Line Impedances & $10 \mathrm{~m} \Omega, 0.3 \mathrm{mH}$ \\
\hline $\mathrm{C}_{\mathrm{dc}}, \mathrm{U}_{\mathrm{dc}}$ & DC-Link Size \& Voltage & 5mf, $750 \mathrm{~V}$ \\
\hline $\mathrm{K}_{\mathrm{p} 1} \& \mathrm{~K}_{\mathrm{i} 1}$ & Proportional \& Integral Gain & $0.88 \& 78.96$ \\
\hline $\mathrm{K}_{\mathrm{p} 2} \& \mathrm{~K}_{\mathrm{i} 2}$ & Proportional \& Integral Gain & $160 \& 29578$ \\
\hline Ts & Sampling Time & $55 \mu \mathrm{S}$ \\
\hline $\mathrm{K}_{1} \& \mathrm{~K}_{2}$ & STF Gain & $100 \& 40$ \\
\hline$f_{s}$ & Switching Frequency & $14 \mathrm{kHz}$ \\
\hline Load $_{1}$ & Non-Linear Load Res. and Cap. & $16 \Omega, 80 \mu \mathrm{F}$ \\
\hline $\operatorname{Load}_{2}$ & Non-Linear Load Res. and Cap. & $20 \Omega, 80 \mu \mathrm{F}$ \\
\hline $\operatorname{Load}_{3}$ & Non-Linear Load Res. and Cap. & $18 \Omega, 80 \mu \mathrm{F}$ \\
\hline $\operatorname{Load}_{4}$ & Linear Resistor Load & $40 \Omega$ \\
\hline Load $_{5}$ & Non-Linear Load Res. and Ind. & $16 \Omega, 30 \mathrm{mH}$ \\
\hline
\end{tabular}

In this study, the distorted and un-balanced grid voltages are used. This non ideal grid voltage is generated by the equation given in (17). In this case, voltage total harmonic distortions $\left(\mathrm{THD}_{\mathrm{u}}\right)$ in each phase of the grid are found to be $10.80 \%, 12.79$ $\%, 8.13 \%$ respectively which can be considered typical considering the range of voltage THDs considered in the literature [35-39]. and the RMS value of the phase voltages $\left(u_{a}, u_{b}, u_{c}\right)$ are $240 \mathrm{~V}, 226 \mathrm{~V}$ and $247 \mathrm{~V}$.

$$
\left.\begin{array}{c}
u_{a}=\sqrt{2} 240 \sin (w t)+30 \sin (5 w t)+20 \sin (7 w t)+7 \sin (11 w t) \\
u_{b}=\sqrt{2} 226 \sin \left(w t-\frac{2 \Pi}{3}\right)+35 \sin \left(5 w t-\frac{2 \Pi}{3}\right)+9 \sin \left(7 w t-\frac{2 \Pi}{3}\right)+10 \sin \left(11 w t-\frac{2 \Pi}{3}\right) \\
u_{c}=\sqrt{2} 247 \sin \left(w t+\frac{2 \Pi}{3}\right)+19 \sin \left(5 w t+\frac{2 \Pi}{3}\right)+15 \sin \left(7 w t+\frac{2 \Pi}{3}\right)+13 \sin \left(11 w t+\frac{2 \Pi}{3}\right)
\end{array}\right\}
$$




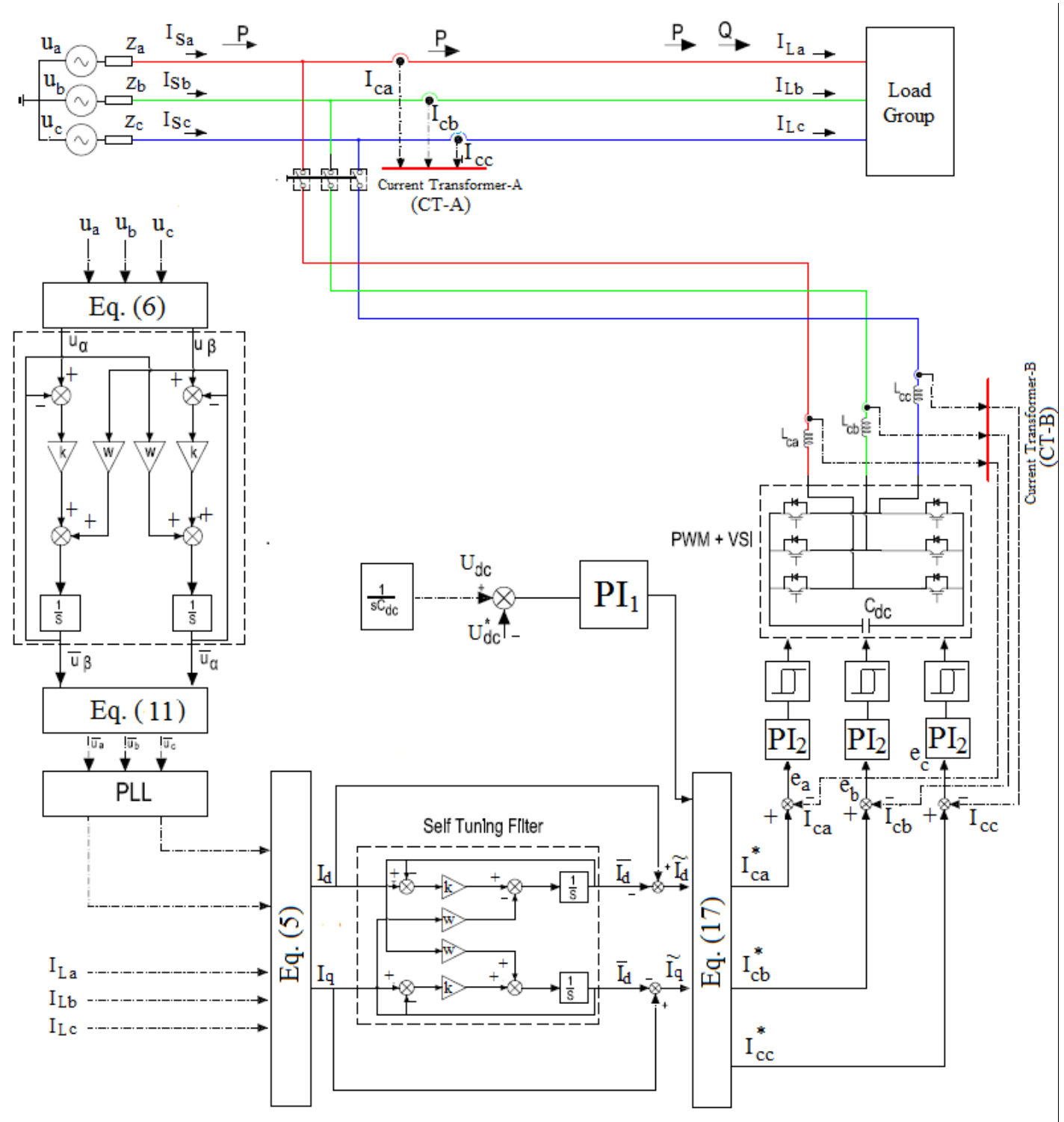

Fig. 1. Block diagram of the APF and proposed control method

\section{Computer Simulated and Real-Time Experimental Results}

To demonstrate the performance of the proposed control method, results from both the numerical simulation and real-time experimentation are presented here. Section 5.1 presents MATLAB / Simulink simulation results comparing the proposed control method with a state-of-the-art technique in [19], as well as the well-known $p q$ and $d q$ methods. In particular, the effect of non-ideal supply conditions on the performance of APF is investigated. In Section 5.2, results are presented from testing the proposed control method and power system using the RT-LAB real-time platform. 


\subsection{Simulation Results}

In this section, the performance of the proposed method is compared to that of the prior art for both ideal and non-ideal grid voltage conditions. As seen in Fig. 2 (a), the grid voltage waveform is purely sinusoidal. In contrast, the non-ideal grid voltage waveform is generated by using (17), as shown in Fig. 2 (b).

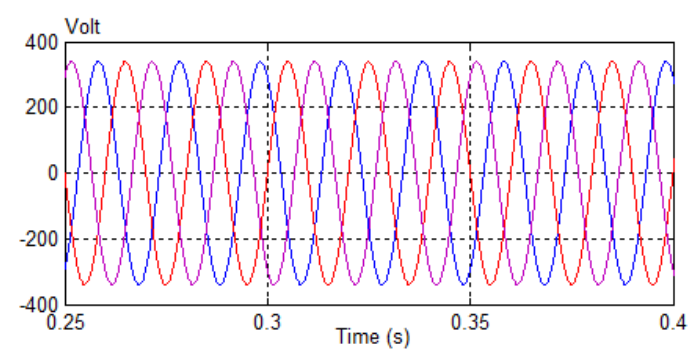

a-)

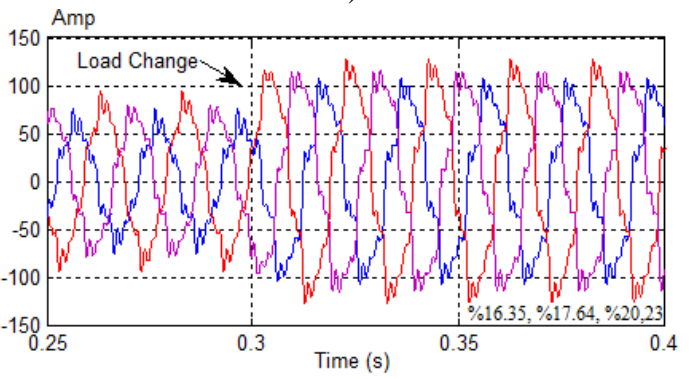

C-)

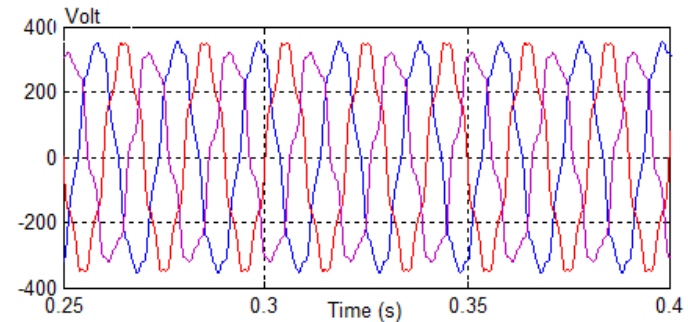

b-)

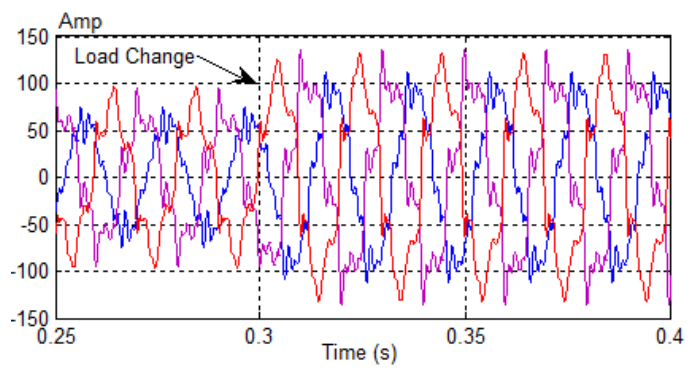

d-)

Fig. 2. Voltage and current waveforms, a-) ideal grid voltage, b-) non-ideal (distorted and unbalanced) grid voltage, c-) load currents under ideal grid voltage, d-) load currents under non-ideal grid voltage

The non-ideal grid voltage considered in Fig. 2 (b) is 3\% unbalanced and has a THD of $10 \%$. The load current waveforms under ideal grid voltage conditions can be seen in Fig. 2 (c). Fig. 2 (d) shows the harmonic distortions on the load current change depending on the distortion present on the grid. Notice that, depending on the load, current THD varies within 16 to $21 \%$.

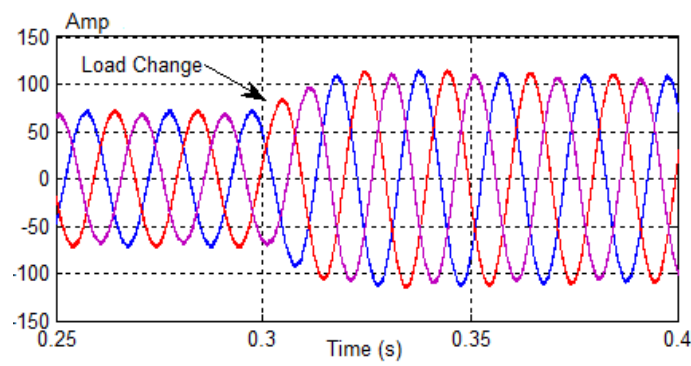

a-)

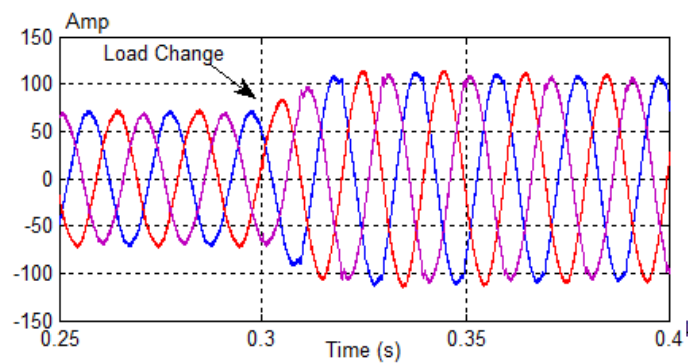

b-) 


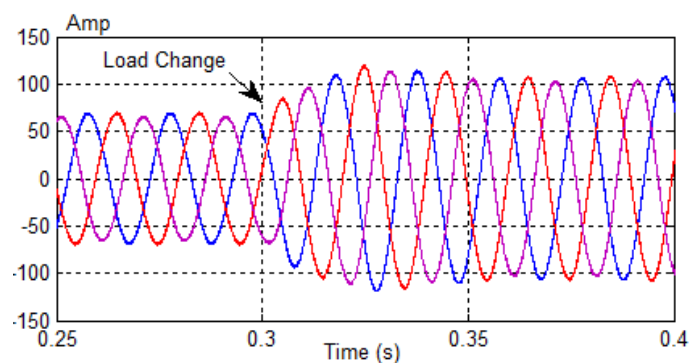

$\mathrm{c}-$ )

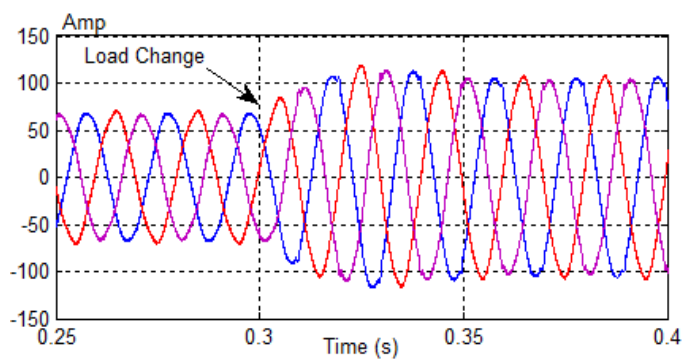

d-)

Fig. 3. Compensation of the grid current harmonics by using conventional dq method: a-) under ideal voltage, b-) under non-ideal voltage, and by using conventional pq method: c-) under ideal voltage, d-) under non-ideal voltage,

Fig. 3 shows grid current waveforms after harmonic compensation by the two conventional methods, $d q$ and $p q$, for both ideal and non-ideal grid voltage conditions. Under ideal grid voltage conditions, the grid currents are well compensated by both the dq (see Fig. 3 (a)) and pq method (see Fig. 3 (c)). For these cases, as seen in Table II, the THD of the grid currents are reduced from around $20 \%$ to around $2 \%$.

However, for the non-ideal grid conditions, their performances are not acceptable. As can be seen from Table II, the THD of the grid currents decreases from around $20 \%$ to around 7\% with $d q$ method (see Fig. 3 (b)) and $10 \%$ with pq theory (see Fig 3 (d)). It is clear that the non-ideal supply condition adversely affects the behaviour of the APF while using conventional $p q$ theory and the $d q$ method.

This problem has been investigated extensively in the literature with various control strategies proposed, one of which is the STF-pq method adopted in [19]. In Figs. 4 (a) and (b), we see that the STF-pq method displays good performance under both ideal and non-ideal grid voltage conditions, as attested in [19]. Table II shows that the THD of the grid currents are reduced to around $2 \%$, for both grid voltage conditions.

Table II. APF Performance Operation Scenarios Cooperation with Control Methods

\begin{tabular}{|c|c|c|c|c|c|c|c|c|c|c|c|c|c|}
\hline \multirow{3}{*}{\multicolumn{2}{|c|}{$\begin{array}{c}\text { Methods } \\
\text { \& } \\
\text { Conditions }\end{array}$}} & \multicolumn{3}{|c|}{$d q$} & \multicolumn{3}{|c|}{$p q$} & \multicolumn{3}{|c|}{ STF-pq [19] } & \multicolumn{3}{|c|}{ Proposed Method } \\
\hline & & \multicolumn{3}{|c|}{$\begin{array}{l}\text { Currents THD of } \\
\text { Phases (\%) }\end{array}$} & \multicolumn{3}{|c|}{$\begin{array}{c}\text { Currents THD of } \\
\text { Phases (\%) }\end{array}$} & \multicolumn{3}{|c|}{$\begin{array}{c}\text { Currents THD of Phases } \\
(\%)\end{array}$} & \multicolumn{3}{|c|}{$\begin{array}{l}\text { Currents THD of } \\
\text { Phases (\%) }\end{array}$} \\
\hline & & $\mathbf{a}$ & b & C & A & b & C & a & b & C & $\mathbf{a}$ & b & C \\
\hline \multirow{2}{*}{ 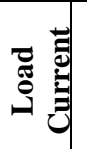 } & Ideal & 16.35 & 17.64 & 20.23 & 16.35 & 17.64 & 20.23 & 16.35 & 17.64 & 20.23 & 16.35 & 17.64 & 20.23 \\
\hline & Non-Ideal & 22.04 & 29.73 & 18.20 & 22.04 & 29.73 & 18.20 & 22.04 & 29.73 & 18.20 & 22.04 & 29.73 & 18.20 \\
\hline \multirow{2}{*}{ 을 } & Ideal & 2.38 & 2.42 & 1.66 & 1.68 & 1.88 & 1.89 & 1.69 & 1.76 & 1.73 & 1.66 & 1.73 & 1.66 \\
\hline & Non-Ideal & 6.46 & 7.41 & 5.73 & 9.90 & 9.98 & 6.01 & 2.50 & 2.57 & 2.19 & 2.30 & 2.64 & 2.16 \\
\hline
\end{tabular}


Fig. 4 (c) and (d) show the grid current waveforms after harmonic compensation by the proposed method in this paper under ideal and non-ideal voltage conditions, respectively. Results show that the harmonic compensation performance of the proposed method is comparable to that of the STF- $p-q$ method. The THD of the grid currents for both STF-based methods are reduced to $2 \%$ under both grid voltage conditions, which meets the IEEE 519-1992 recommended standard.

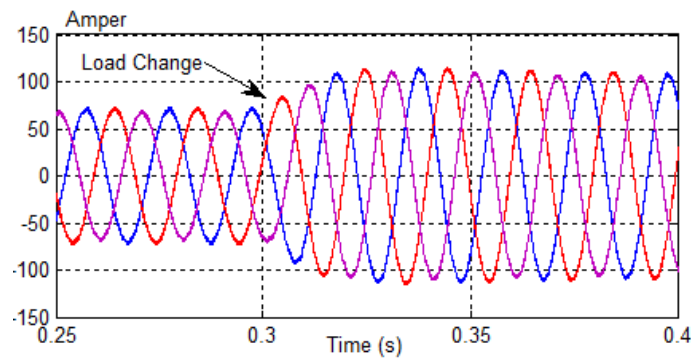

a-)

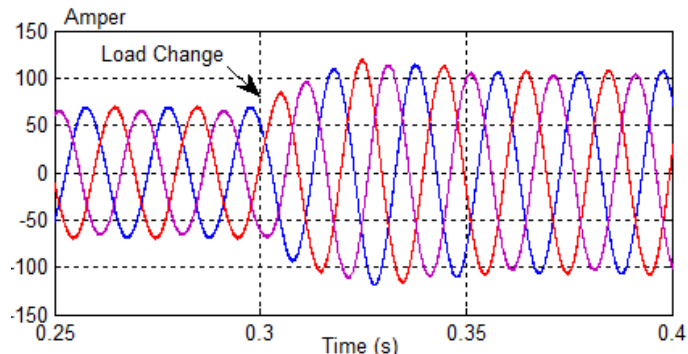

c-)

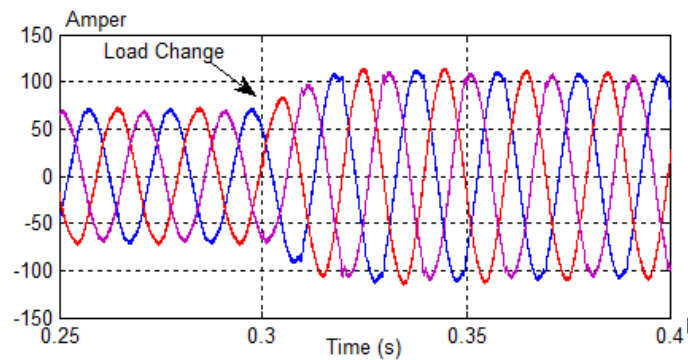

b-)

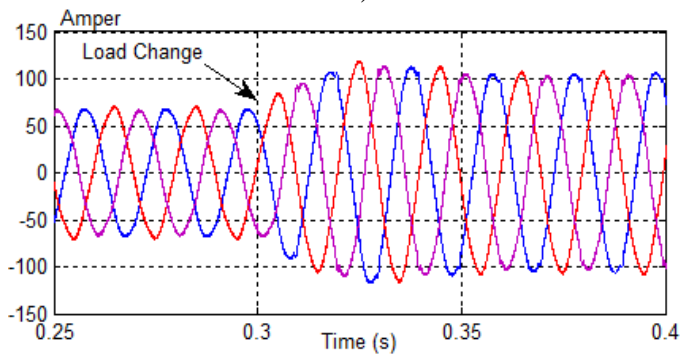

d-)

Fig. 4. Compensation of the grid current harmonics a-) by using STF based $p q$ theory under ideal voltage, b-) by using STF based $p q$ theory under ideal voltage, c-) by using proposed method under ideal voltage, d-) by using proposed method under non-ideal voltage

A graphical depiction of the remnant distortion after compensation by the various methods, for phases $a, b$ and $c$ is shown, respectively, in Figs. 5 (a), (b) and (c). The benefit offered by our technique is that the performance improvement is achieved through use of a simpler structure. 


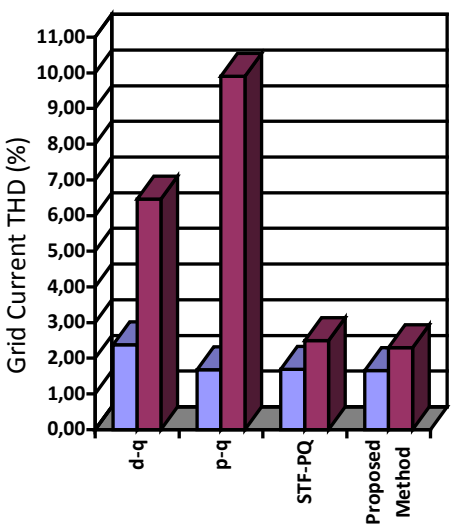

a-)

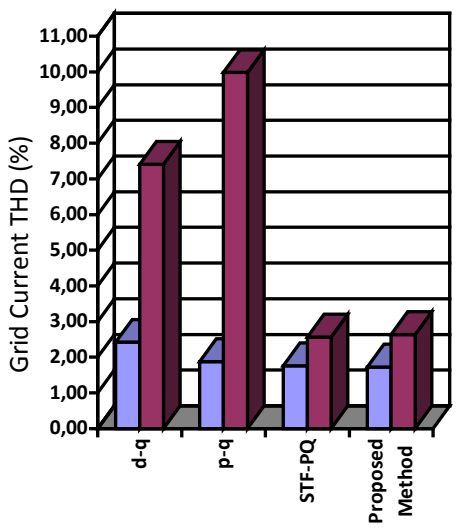

b-)

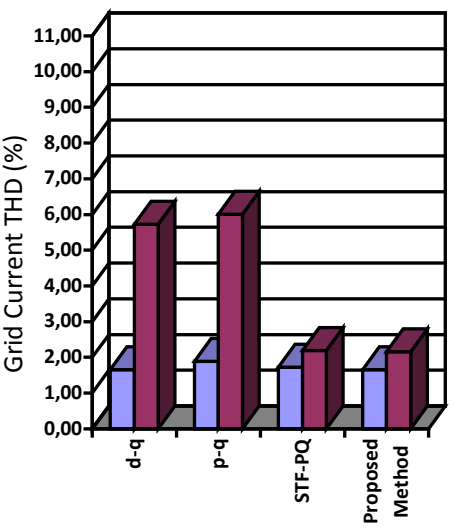

C-)

Fig.5. Performance comparison of the control methods, a-) phase-a, b-) phase-b, c-) phase-c, (Blue bars are for ideal grid voltage condition, red bars are non-ideal grid voltage condition

\subsection{Real-Time Control in Software-in-the-Loop (SIL ) Configuration}

The proposed control method and power system have been modelled in Simulink using RT-LAB real-time platform and associated tools to observe the performance in a real time environment. RT-LAB allows for the distributed simulation of complex power systems. Specifically, the proposed system is realized on a field programmable gate array (FPGA) architecture using the Xilinx system generator toolbox. The system is then tested in software-in-the-loop (SIL) in hardware synchronization mode, which is similar to the hardware-in-the-loop (HIL) test giving due consideration for delay in the real time measurement of actual signals and implementation of the control signals. Fig. 6 shows the real-time laboratory setup using the OPAL-RT (OP5600) platform, which manages the communications between the CPUs, FPGA architecture and the console PC (from which the global simulation is controlled). 


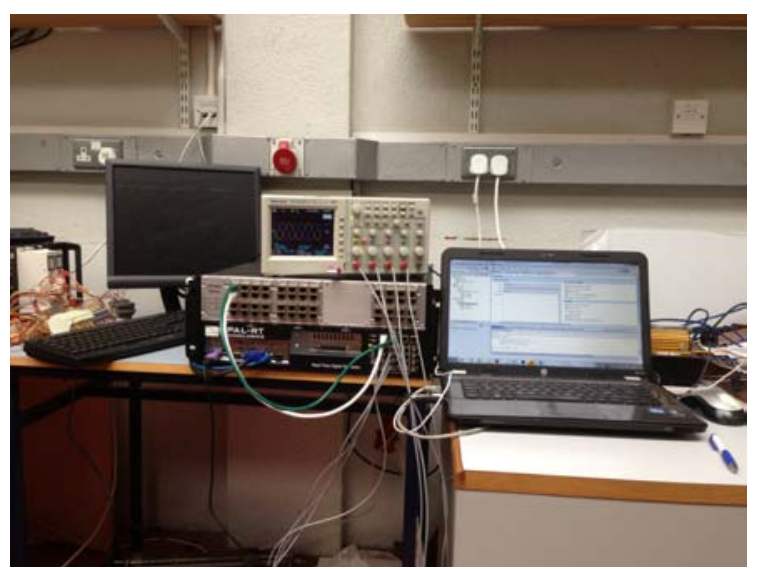

Fig.6 Experimental setup with the OPAL-RT

As seen in Fig. 7 (a), the grid voltage waveform is not purely sinusoidal. Therefore, after transformation of this waveform to the $\alpha-\beta$ coordinate system via (6) the grid voltage waveform as shown in Fig 7 (b) is also not sinusoidal. As mentioned earlier, this distorted voltage has a detrimental effect on the control system, which degrades the harmonic suppression performance of the converter.

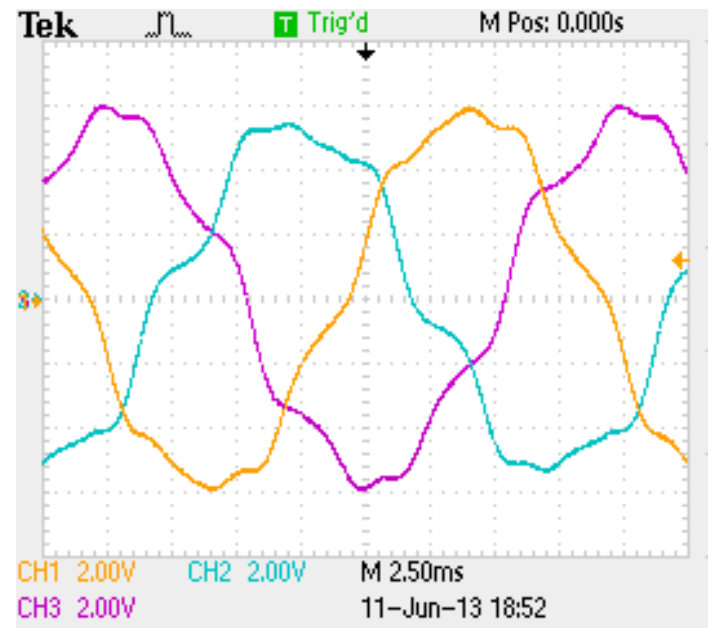

Fig. 7 (a). Three phase unbalanced and distorted (non-ideal) grid voltages $\left(u_{a}, u_{b}, u_{c}\right)$ (scale: $113 \mathrm{~V} /$ div.)

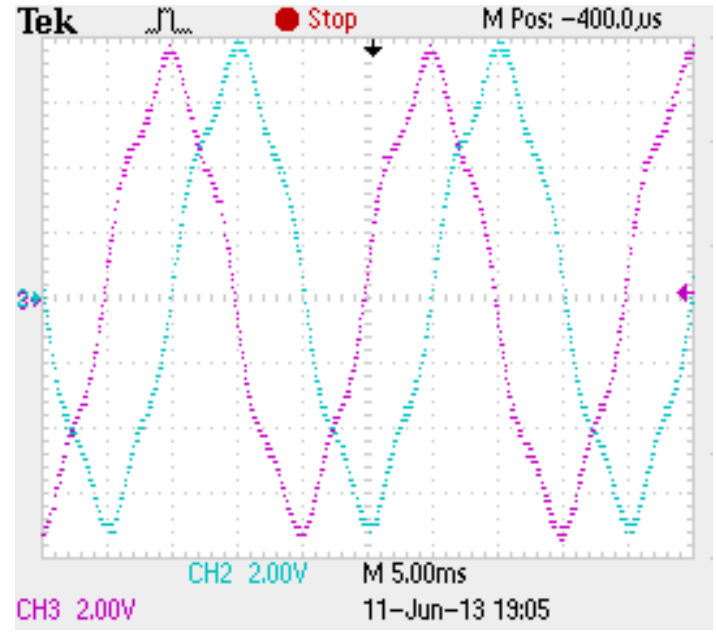

Fig. 7 (b). Grid voltages after transformation to $\alpha-\beta$ coordinate system $\left(u_{\alpha}, u_{\beta}\right)$, (scale: $113 \mathrm{~V} /$ div.) 


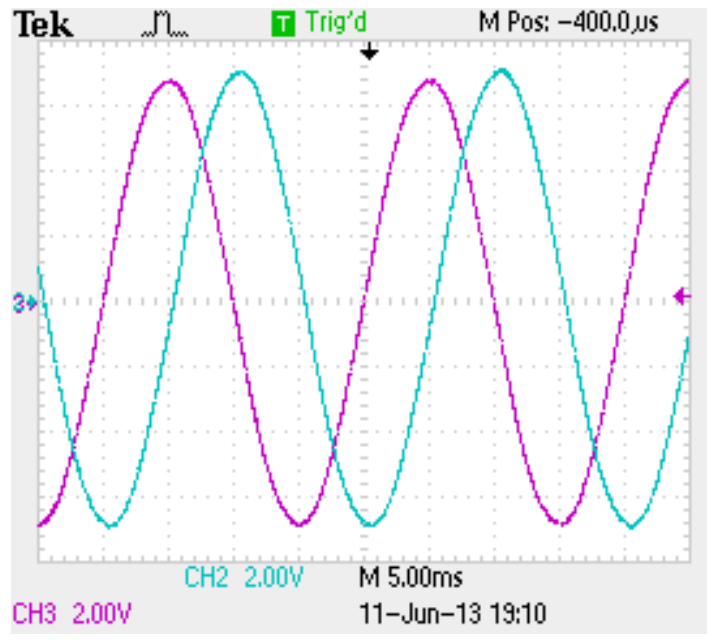

Fig. 7 (c). Output signal of the $\operatorname{STF}\left(\bar{u}_{\alpha}, \bar{u}_{\beta}\right)$ (scale: $113 \mathrm{~V} /$ div.)

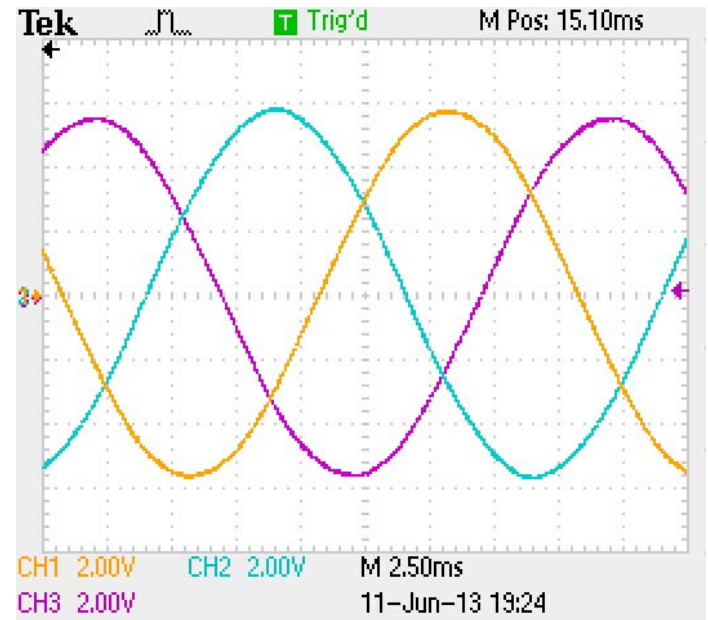

Fig. 7 (d). The obtained three phase balanced and un-distorted (ideal) voltage signals for the control system $\left(\bar{u}_{a}, \bar{u}_{b}, \bar{u}_{c}\right)$ (scale: $113 \mathrm{~V} /$ div.)

As discussed in Section 3, this problem can be rectified by using the STF. The two phase grid voltages are filtered using (9) and (10) to obtain undistorted and balanced waveforms - see Fig. 7 (c). It can be seen that, there is no phase displacement between the input and output waveforms, which is a major advantage offered by this method. The obtained undistorted and ideal two phase voltage waveforms are then transformed to three phase voltage waveforms via (11), shown in Fig. 7 (d). Finally, the correct angular position of the synchronous references can be calculated using a standard PLL.

The THD of the load currents $\left(\operatorname{Load}_{1}, \operatorname{Load}_{2}, \operatorname{Load}_{3}, \operatorname{Load}_{4}\right)$ in each phase are $26.03 \%, 29.98 \%$ and $20.47 \%$, while the rms currents are $54.74 \mathrm{~A}, 48.85 \mathrm{~A}, 41.68 \mathrm{~A}$. After connection of Load 5, the $\mathrm{THD}_{\mathrm{i}}$ changed to $22.05 \%, 29.82 \%, 18.21 \%$ and the currents obtained are 80.67 A, 73.87 A, 67.65 A . The load current waveforms can be seen in Fig. 8. 


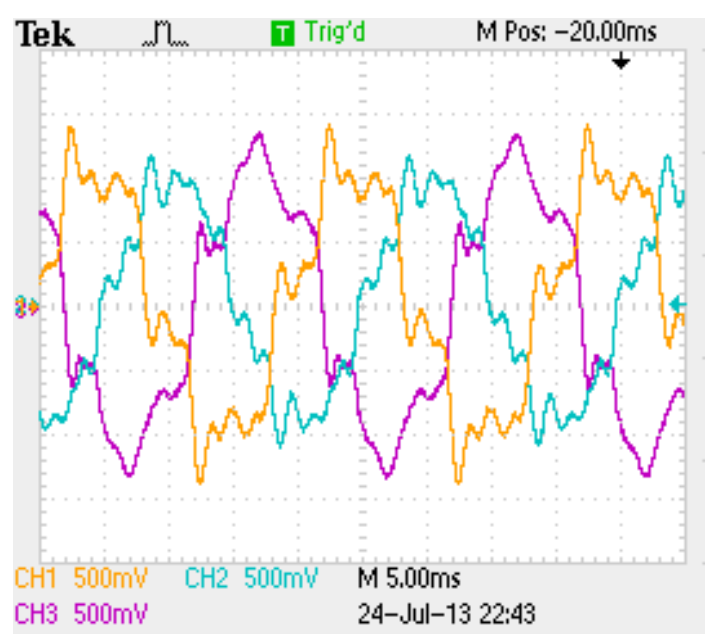

Fig. 8. Three phase non-linear load currents (scale: $47 \mathrm{~A} /$ div.)

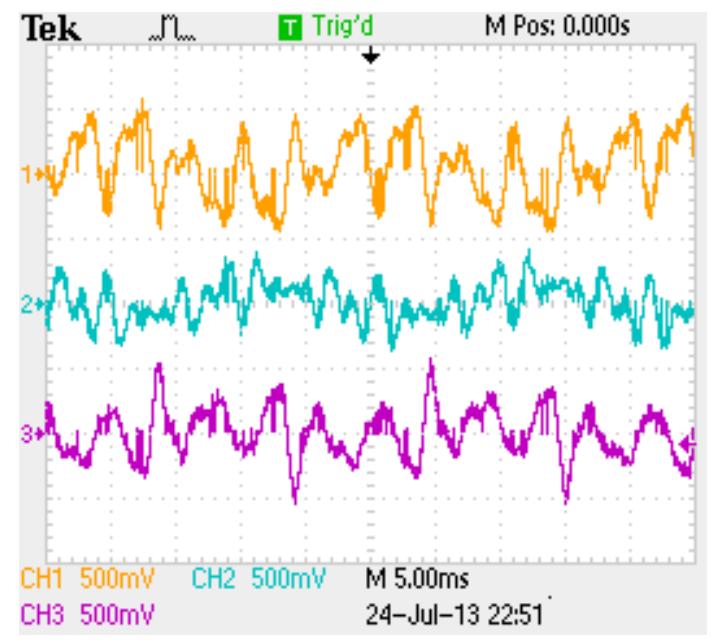

Fig. 9. Injected converter currents by the proposed control method (scale: $47 \mathrm{~A} /$ div.)

In the second step of the controller, the $i_{d}$ and $i_{q}$ components can be calculated by way of (4). The calculated currents consist of fundamental and harmonics components. In order to extract harmonic components, the second STF is designed as in (12) and (13). Therefore, the $i_{d}$ and $i_{q}$ components are processed in order to obtain, the balanced $\bar{i}_{d}$ and $\bar{i}_{q}$ components at the fundamental frequency. The harmonic components are subtracted from the fundamentals to obtain two phase converter reference currents. No additional low-pass or high-pass filter is required for this purpose. Then, the obtained two phase reference current signals are converted to three phase by using (16). Injected converter currents can be seen in Fig. 9. Finally, the grid current waveforms are obtained as given in Fig. 10. As a result, the THD of the grid currents are reduced from $26.03 \%, 29.98 \%, 20.47 \%$ to $4.12 \%, 4.53 \%, 4.18 \%$ in the first load combinations $\left(\operatorname{Load}_{1}, \operatorname{Load}_{2}, \operatorname{Load}_{3}\right.$ and Load $)$. The grid current THD are measured as 3.64 \%, 4.18 $\%, 3.64 \%$ after the connection of Load $_{5}$. Since the reactive power consumed is compensated for by the APF, the grid current is in phase with voltage (Fig. 11). 


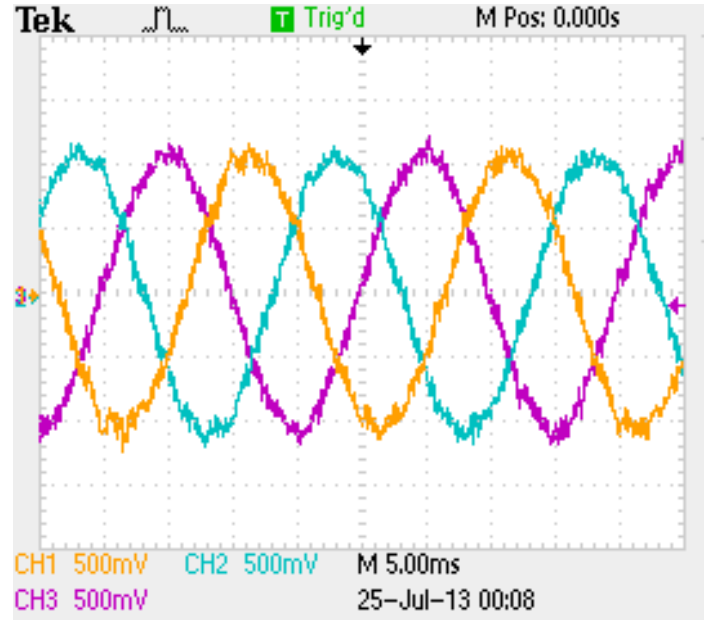

Fig. 10. Grid current after filtering by proposed control method under non- ideal grid voltage and unbalanced nonlinear load currents conditions (scale: $47 \mathrm{~A} / \mathrm{div}$.)

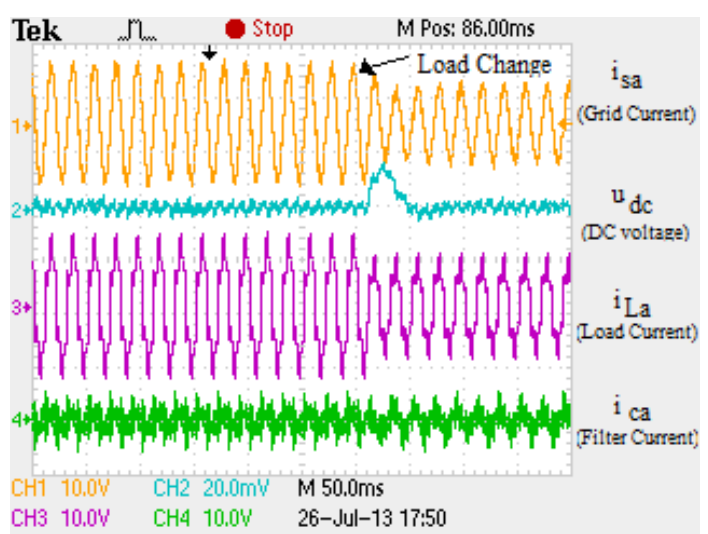

Fig .12 (a). DC-link voltage and current waveforms at phase-a during load increasing (Current scale: $94 \mathrm{~A} /$ div., $10 \mathrm{~V} /$ div.)

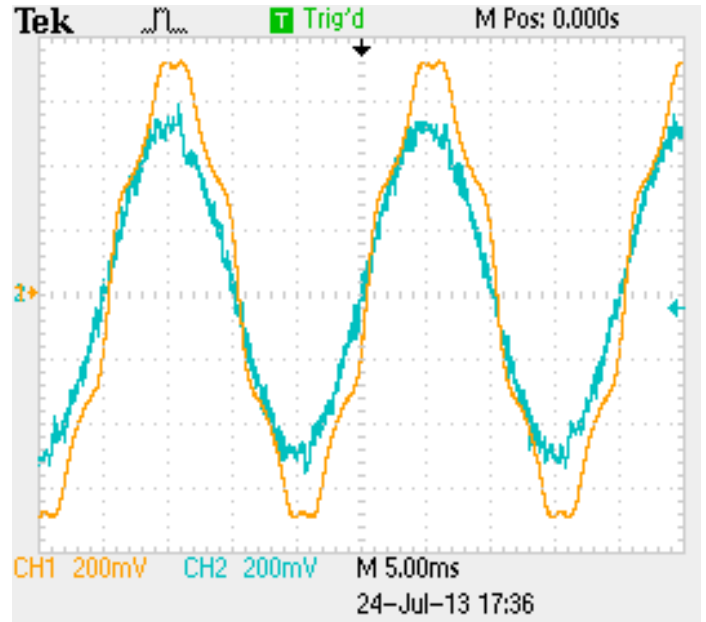

Fig. 11. Grid voltage (yellow plot) and grid current (blue plot) waveform under non-ideal grid voltage condition at phase a after filtering (scale: $35 \mathrm{~A} / \mathrm{div}, 97 \mathrm{~V} / \mathrm{div}$ )

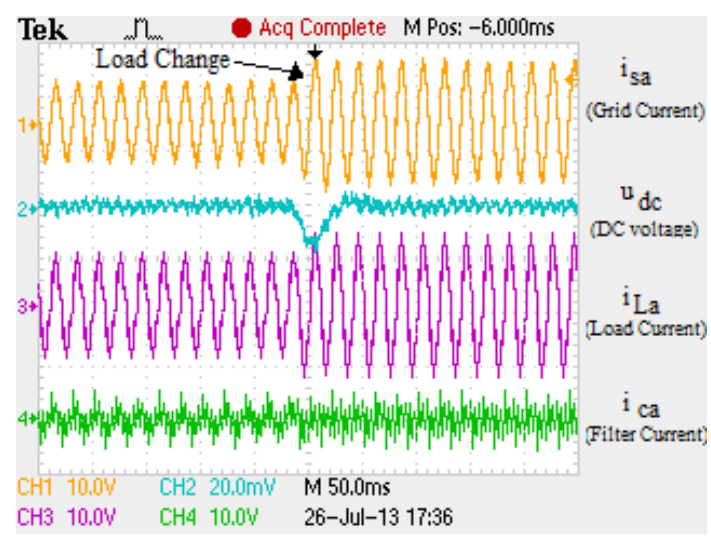

Fig. 12 (b). DC-link voltage and current waveforms at phase-a during load decreasing (Current scale: 94 A/div., 10 V/div.)

Figs. 12 (a) and 12 (b) show the dynamic performance of the system.

It is to be noted that to show the dc link dynamic variation, the pre-settled DC-link capacitor voltage, $U_{d c}^{*}$, is subtracted from the actual measured dc-link capacitor voltage, $u_{d c}$, to obtain instantaneous error, $\Delta u_{d c}$. 
The load change operation comprises the addition of all other loads to create an average load change of $50 \%$. During this operation, the magnitude of the load current changed and the proposed control method compensated the grid current dynamically under both load change conditions. Moreover, the DC-link capacitor voltage (green plot) is maintained as required during the fast load change.

\section{Conclusion}

In this paper, the design of a control method that generates the correct reference current signal in order to satisfy the requirements of harmonic suppression and reactive power compensation, for unbalanced nonlinear load combinations under the case of non-ideal grid voltage conditions have been discussed. An alternate method is proposed where two STF are applied to manage the distorted and unbalanced voltage and current. In the proposed method, the distorted and unbalanced voltages are first processed by using self tuning filter (STF) to determine the correct angular positions. Then a second STF is used to extract balanced load current waveforms This method eliminates the need for additional low-pass or high-pass filtering when extracting harmonic components from the fundamental. A step-by-step performance study, in a real-time environment, shows that the proposed control technique is able to generate the proper compensating reference current during the steady state and dynamic load change conditions under the distorted and unbalanced grid voltage conditions.

\section{Acknowledgements}

The authors acknowledge the financial support by the European Union under contract no: 2012/307-675.

\section{References}

[1] H. Sasaki, T. Machida, "A New Method to Eliminate AC Harmonic Currents by Magnetic Flux CompensationConsiderations on Basic Design," IEEE Transactions on Power Apparatus and Systems, , vol.PAS-90, no.5, pp.2009,2019, Sept. 1971 doi: 10.1109/TPAS.1971.292996

[2] L. Gyugyi, E. C. Strycula, "Active AC Power Filters," in Proc. IEEE Ind. Appl. Ann. Meeting, vol. 19-C, pp. 529-535, 1976.

[3] B. Singh, K. Al-Haddad, A.Chandra " A Review of Active Filters for Power Quality Improvement", IEEE Trans. Industrial Electronics, vol. 46, no. 5, pp. 960-971.

[4] N. Mariun, A. Alam, S. Mahmod, H. Hizam, "Review of Control Strategies for Power Quality Conditioners," National Power and Energy Conference Proceedings., PECon 2004. vol., no., pp. 109- 115, 2930 Nov. 2004. 
[5] Y. Komatsu, T. Kawabata, "A Control Method of Active Power Filter in Unsymmetrical and Distorted Voltage System," Proceedings of the Power Conversion Conference - Nagaoka 1997, vol.1, no., pp.161,168 vol.1, 3-6 Aug 1997. doi: 10.1109/PCCON.1997.645605.

[6] M. Machmoum, N. Bruyant, "Control Methods for Three-Phase Active Power Filters under Non-Ideal Mains Voltages," International Conference on Power System Technology Proceedings, PowerCon 2000., vol.3, no., pp.1613,1618 vol.3, 2000 doi: 10.1109/ICPST.2000.898214.

[7] S. M. Rafiei, H. A.Toliyat, R. Ghazi T. Gopalarathnam, "An Optimal and Flexible Control Strategy for Active Filtering and Power Factor Correction under Non-Sinusoidal Line Voltages," IEEE Transactions on Power Delivery, vol.16, no.2, pp.297,305, Apr 2001 doi: 10.1109/61.915499

[8] D. Cunlu, J. Chongpeng, Z. Xiaoying C. Li, "Harmonic Suppression Using The Improved P-Q Theory in The Power System," International Workshop on Intelligent Systems and Applications, ISA 2009., vol., no., pp.1,4, 23-24 May 2009 doi: 10.1109/IWISA.2009.5072893

[9] H. M. Foisal, B. R. Abdul, "An Improved Active Filter for Distorted Voltage Conditions," Twenty-Eighth Annual IEEE Applied Power Electronics Conference and Exposition (APEC) 2013, vol., no., pp.3186,3193, 1721 March 2013 doi: 10.1109/APEC.2013.6520756

[10] Hyosung Kim, "Control An Active Filter in Unbalanced Non-Sinusoidal Source Voltages," Proceedings of the Power Conversion Conference, PCC-Osaka 2002., vol.2, no., pp.766,771 vol.2, 2002 doi: 10.1109/PCC.2002.997616.

[11] M. Kale, E. Ozdemir, " Harmonic and Reactive Power Compensation with Shunt Active Power Filter Under Non-Ideal Mains Voltage," Electric Power Systems Research 74 (2005) 363-370.

[12] S. M. R. Rafiei, R. Ghazi, H. A. Toliyat, "IEEE-519-Based Real-Time and Optimal Control of Active Filters under Nonsinusoidal Line Voltages Using Neural Networks," IEEE Transactions on Power Delivery, vol.17, no.3, pp.815,821, Jul 2002. doi: 10.1109/TPWRD.2002.1022809

[13] N.K.Nguyen, D. Flieller, P. Wira, D. O. Abdeslam, "Neural Networks for Phase and Symmetrical Components Estimation in Power Systems," 35th Annual Conference of IEEE Industrial Electronics. IECON '09., vol., no., pp.3252,3257, 3-5 Nov. 2009 doi: 10.1109/IECON.2009.5415210.

[14] H. S. Song, "Control Scheme for PWM Converter and Phase Angle Estimation Algorithm under Voltage Unbalance and/or Sag Condition”, Ph.D. Thesis in Electronic and Electrical Engineering. South Korea, 2000.

[15] M. C. Ben Habib, E. Jacquot, and S. Saadate. "An Advanced Control Approach for A Shunt Active Power Filter", International Conference on Renewable Energies And Power Quality (Icrepq'03), 2003.

[16] M. Abdusalam, P. Poure, S. Saadate, "A New Control Scheme of Hybrid Active Filter Using Self-TuningFilter,” International Conference on Power Engineering, Energy and Electrical Drives, POWERENG 2007, vol., no., pp.35-40, 12-14 April 2007.

[17] S. Karimi, P. Poure, S. Saadate, "High Performances Reference Current Generation for Shunt Active Filter under Distorted and Unbalanced Conditions", IEEE -PESC Power Electronics Specialists Conference, vol., no., pp.195,201, 15-19 June 2008.

[18] M. Abdusalam, P. Poure, S. Saadate, "Hardware Implementation of A Three-Phase Active Filter System with Harmonic Isolation Based on Self-Tuning-Filter", Power Electronics Specialists Conference, IEEE-PESC 2008, vol., no., pp.2875,2881, 15-19 June 2008.

[19] M. Abdusalam, P. Poure, S. Karimia, S. Saadatea, "New Digital Reference Current Generation for Shunt Active Power Filter under Distorted Voltage Conditions", Electric Power Systems Research, vol. 79, pp 759-76, 2009.

[20] G. Adam, A. G. Stan, G. Livint, "An Adaptive Hysteresis Band Current Control for Three Phase Shunt Active Power Filter Using Fuzzy Logic", 2012 International Conference and Exposition on Electrical and Power Engineering (EPE), vol., no., pp.324,329, 25-27 Oct. 2012.

[21] N. Gupta, S. P. Dubey, S. P. Singh, "PIL Based Control Algorithm for Three-Phase Four-Wire Active Filter for Reactive and Harmonic Compensation under Distorted Supply", 2010 Joint International Conference on Power Electronics, Drives and Energy Systems, (PEDES) \& 2010 Power India, vol., no., pp.1,6, 20-23 Dec. 2010.

[22] S. Ahmed, G. Madjid, M. Youcef, T. Hamza, "Real Time Control of An Active Power Filter under Distorted Voltage Condition", International Journal of Power Electronics and Drive System (IJPEDS), Vol. 2, No. 4, pp. 424-423, December 2012.

[23] E. Samedaei, H. Vahedi, A. Sheikholeslami, S. Lesan, "Using STF-PQ Algorithm and Hysteresis Current Control in Hybrid Active Power Filter To Eliminate Source Current Harmonic", Power Quality Conference (PQC), pp.1-6, 2010.

[24] E. Samadaei, S. Lesan, S. M. Cherati, "A New Schematic for Hybrid Active Power Filter Controller," 2011 IEEE Applied Power Electronics Colloquium (IAPEC), vol., no., pp.143,148, 18-19 April 2011.

[25] S.Biricik, O.C.Ozerdem, S.Redif and M.O.I.Kmail, " Performance Improvement of Active Power Filters Based on P-Q and D-Q Control Methods under Non-Ideal Supply Voltage Conditions", 7th International Conference on Electrical and Electronics Engineering (ELECO 2011), 1-4 Dec. 2011, Bursa, Turkey 
[26] O.C.Ozerdem, S.Biricik "Control of Shunt Active Filter under Non-Ideal Grid Volage and Un-Balanced Load Conditions”, Electrical, Electronics and Computer Engineering, (ELECO 2012), 29 Nov.-01 Dec. 2012, Turkey (in Turkish).

[27] A. Benaissa, B. Rabhi, M. F. Benkhoris, A. Moussi, J. Le Claire, "Fuzzy Logic Controller for Five-Level Shunt Active Power Filter under Distorted Voltage Conditions," 38th Annual Conference on IEEE Industrial Electronics Society IECON 2012, vol., no., pp.4973,4978, 25-28 Oct. 2012.

[28] I. Ghadbane, A. Ghamri, M. T. Benchouia, A. Golea, "Three-Phase Shunt Active Power Filter for Power Improvement Quality Using Sliding Mode Controller", 2nd International Conference on Communications, Computing and Control Applications (CCCA), vol., no., pp.1,6, 6-8 Dec. 2012.

[29] A. Ghamri , M. T. Benchouia \& A. Golea "Sliding-Mode Control Based Three-Phase Shunt Active Power Filter", Simulation and Experimentation, Electric Power Components and Systems, 40:4, 383-398, Jan. 2012.

[30] S.Biricik, O.C.Ozerdem, S.Redif and M.O.I.Kmail, "Novel Hybrid Active Power Filter Structure To Compensate Harmonic Currents and Reactive Power", 16th IEEE Mediterranean Electro-technical Conference MELECON 2012, 25-28 Mart 2012, Tunisia.

[31] S.Biricik, O.C.Ozerdem, S.Redif and M.O.I.Kmail, "Performance Improvement of Active Power Filter under Distorted and Unbalanced Grid Voltage Conditions”, Journal of Electronics and Electrical Engineering (Elektronika ir Elektrotechnika), ISSN 1392 - 1215, Vol. 19, No.1, 2013 pp 35-39.

[32]S.Biricik, S.Redif, O.C.Ozerdem, Malabika Basu, "Control of the Shunt Active Power Filter under Non-Ideal Grid Voltage and Unbalanced Load Conditions"48th International Universities Power Engineering Conference, UPEC 2013, 2-5 September, Dublin, Ireland.

[33] S. S. Patnaik, A.K.Panda, "Real-Time Performance Analysis and Comparison of Various Control Schemes for Particle Swarm Optimization-Based Shunt Active Power Filters", Electrical Power and Energy Systems 52 (2013) 185-197.

[34] H. Akagi, Y. Kanazawa, A. Nabae "Instantaneous reactive power compensators comprising switching devices without energy storage components”, IEEE Transactions on Industry Applications, vol.IA-20, no.3, pp. 625630, 1984.

[35] J. Eloy-Garcia, S. Arnaltes, J.L Rodriguez-Amenedo, "Direct power control of voltage source inverters with unbalanced grid voltages", IET-Power Electronics, vol.1, no.3, pp.395,407, September 2008.

[36] Y. Xu, L.M. Tolbert, J.D. Kueck, D.T. Rizy, "Voltage and current unbalance compensation using a static var compensator," IET-Power Electronics, vol.3, no.6, pp.977,988, November 2010

[37] P. Kanjiya, V. Khadkikar, H.H. Zeineldin, "A Noniterative Optimized Algorithm for Shunt Active Power Filter Under Distorted and Unbalanced Supply Voltages", IEEE Transactions on Industrial Electronics, , vol.60, no.12, pp.5376,5390, December 2013.

[38] B. Rahmani, M.B.Tavakoli, "Reciprocal effects of the distorted wind turbine source and the shunt active power filter: full compensation of unbalance and harmonics under 'capacitive non-linear load' condition", IET-Power Electronics, vol.6, no.8, pp.1668,1682, September 2013.

[39] P. Kanjiya, B. Singh, A. Chandra, K. Al-Haddad, "SRF Theory Revisited” to Control Self-Supported Dynamic Voltage Restorer (DVR) for Unbalanced and Nonlinear Loads", IEEE Transactions on Industry Applications, vol.49, no.5, pp.2330,2340, Sept.-Oct. 2013. 